\title{
Recurrent oral cancer: current and emerging therapeutic approaches
}

\author{
Sabrina Daniela da Silva ${ }^{1,2,3}$, Michael Hier ${ }^{1}$, Alex Mlynarek ${ }^{1}$, Luiz Paulo Kowalski ${ }^{4}$ and \\ Moulay A. Alaoui-Jamali ${ }^{2,3}$ *
}

${ }^{1}$ Department of Otolaryngology-Head and Neck Surgery, Sir Mortimer B. Davis-Jewish General Hospital, McGill University, Montreal, QC, Canada

2 Department of Medicine, Segal Cancer Centre and Lady Davis Institute for Medical Research, Sir Mortimer B. Davis-Jewish General Hospital, McGill University, Montreal, QC, Canada

${ }^{3}$ Department of Oncology, Segal Cancer Centre and Lady Davis Institute for Medical Research, Sir Mortimer B. Davis-Jewish General Hospital, McGill University, Montreal, QC, Canada

${ }^{4}$ Department of Head and Neck Surgery and Otorhinolaryngology, AC Camargo Hospital, São Paulo, São Paulo, Brazil

\section{Edited by:}

Gerald Batist, McGill University,

Canada

Reviewed by:

Brion William Murray, Pfizer Oncology Research, USA

Rayudu Gopalakrishna, University of

Southern California, USA

${ }^{*}$ Correspondence:

Moulay A. Alaoui-Jamali,

Departments of Medicine and

Oncology, Segal Cancer Centre and

Lady Davis Institute for Medical

Research, Sir Mortimer B.

Davis-Jewish General Hospital, McGill

University, 3755 Côte Ste-Catherine

Road, Montreal, OC, Canada

H3T 1 E2.

e-mail: moulay.alaoui-jamali@mcgill.ca
Oral cavity cancer (OCC) is associated with high incidence of loco-regional recurrences, which account for the majority of treatment failures post-surgery and radiotherapy. The time-course of relapse manifestation and metastasis are unpredictable. Relapsed OCC represents a major clinical challenge in part due to their aggressive and invasive behaviors. Chemotherapy remains the only option for advanced OCC whenever salvage surgery or re-irradiation is not feasible, but its efficacy is limited as a result of the drug resistance development. Alternatives to use of different permutations of standard cytotoxic drugs or combinations with modulators of drug resistance have led to incremental therapeutic benefits. The introduction of targeted agents and biologics against selective targets that drive cancer progression has opened-up optimism to achieve superior therapeutic activity and overcome drug resistance because, unlike the non-selective cytotoxic, the target can be monitored at molecular levels to identify patients who can benefit from the drug. This review discusses the multifactorial aspects of clinical drug resistance and emerging therapeutic approaches in recurrent OCC, emphasizing recent advances in targeted therapies, immunotherapy, and potential relevance of new concepts such as epithelial-mesenchymal transition and cancer stem cell hypothesis to drug resistance.

Keywords: oral cancer, recurrence, drug resistance, novel therapeutics

\section{ORAL CANCER RECURRENCE AND THERAPEUTIC MODALITIES}

Oral cavity cancer (OCC) is the most common site of malignancy in the head and neck being ranked as the eightieth most frequent cancer worldwide (Petersen, 2009) with over 145,500 deaths per year ${ }^{1}$ [International Agency for Research on Cancer (IARC; 2011)]. The main risk factors are exposure to exogenous carcinogens such as tobacco smoke and excessive alcohol consumption. The incidence varies among geographical regions, e.g., high incidence is reported in India, France, and South/Southeast Asia (Parkin et al., 2005; Su et al., 2006). OCC has a high occurrence of clinically occult ipsilateral or bilateral lymph node metastasis due to the rich lymphatic submucosal plexus that freely communicates across the midline facilitating the spread of neoplastic cells to any area of the neck (Fan et al., 2011). Most patients with OCC are diagnosed with tumors at advanced stage and incur significant morbidity and mortality due to the disease as well as sequels associated with therapeutic management and complications (Kowalski et al., 1998, 2005). The overall survival rate decreases as the carcinoma stage increases, from 75 to $90 \%$ for Stage I to $10-22 \%$

${ }^{1}$ http://www.iarc.fr/study_booklptrivandrum.php for Stage IV (Kowalski et al., 2005). The prognosis depends on tumor primary site, nodal involvement, tumor thickness, and the status of the surgical margins (Garzino-Demo et al., 2006). Conventional treatment for OCC includes surgery, radiotherapy, and chemotherapy. OCC surgical management often can lead to severe morbidity due to disfiguring and functional side effects (Furness et al., 2011). Surgery combined with chemotherapy and radiotherapy can improve overall survival, particularly in patients with advanced oral cancers. Induction chemotherapy may prolong survival by up to $20 \%$ and adjuvant concomitant chemoradiotherapy can improve survival by up to $16 \%$ (Furness et al., 2011). However, approximately one-third of patients treated with surgery and adjuvant therapy will experience local or regional recurrence and/or distant metastasis (Greenberg et al., 2003).

Local and regional recurrences account for up to $90 \%$ of treatment failures post-surgery and radiotherapy (Leemans et al., 1994; Carvalho et al., 2005; Agra et al., 2010). The rates of OCC recurrence vary from 18 to $76 \%$ for patients who underwent standard treatment, and it is considered the major cause of poor survival rates. Most studies corroborated that the median time to recurrence is 7.5 months after treatment, and $86 \%$ of the recurrences occur within 24 months (Carvalho et al., 2005; Kowalski et al., 2005; Fan et al., 2011). The presence of cervical lymph nodes 
metastasis is the most important adverse prognostic factor in OCC patients. Extracapsular spread is a particularly reliable predictive factor of loco-regional recurrence, distant metastasis, and death from disease (Greenberg et al., 2003). In this subset of patients, adjuvant chemoradiation proved to reduce the rates of recurrences when compared to radiation alone (Bernier et al., 2008). The histological status of surgical margins is another available assessment for recurrence risk in OCC (Leemans et al., 1994). Woolgar et al. (1999) reported that $\sim 10 \%$ patients with oral squamous cell carcinoma develop recurrence and the relapse appears much earlier than metachronous disease carrying the worst prognosis. Patients with recurrent carcinomas pose a clinical challenge with regard to defining the best therapeutic options. Only a small group of patients are candidates for salvage surgery and about $30-45 \%$ of these have poor survival rates (Agra et al., 2010). Patients who are not candidates for salvage surgery or re-irradiation usually receive chemotherapy, but even with the most recent combinations of drugs the prognosis remains poor and cure is rare (Vermorken et al., 2007). Clearly, new therapeutic options for recurrent OCC are urgently needed. A significant problem in those cases is postoperative and postradiotherapy fibrosis that precludes achieving adequate pharmacologic doses of the drug in the recurrent tumor site.

\section{RESISTANCE TO CHEMOTHERAPY DRUGS IN OCC}

The most common chemotherapy drugs used for advanced OCC include taxanes (paclitaxel and docetaxel), anthracyclines (adriamycin, epirubicin, and pirarubicin), platinums (cisplatin and carboplatin), and antimetabolites (e.g., methotrexate, and 5fluorouracil). Anthracyclines act primarily by interfering with DNA replication via interaction with topoisomerases, intercalation, and induction of DNA strand breaks. Platinum-containing compounds in particular cisplatin and carboplatin target DNA forming intra-strand and inter-strand cross-links causing distortion of the DNA helix and apoptotic cell death. Taxanes such as paclitaxel and taxotere, and vinca alkaloids such as vinorelbine and vincristine all interfere with microtubule and spindle assembly. Topoisomerase inhibitors (e.g., etoposide, topotecan, irinotecan) induce DNA strand breaks, while antimetabolites (e.g., gemcitabine, 5-FU, capecitabine, trimetrexate) are potent inhibitors of RNA synthesis. Exposure of cancer cells to chemotherapeutic agents culminate in the activation of tumor cell apoptosis and most are preferentially active on proliferating "cycling" cancer cells compared to "resting" normal cells making malignant cells marginally susceptible to these agents (Alaoui-Jamali et al., 2004). However, host toxicity can result in part through affect on normal bone marrow stem cells and epithelial cells that are mitotically active and hence susceptible to non-desirable cytotoxic effects of chemotherapeutic agents.

Empiric clinical trials have defined the standard first-line chemotherapeutic regimens and dosage that achieve the best therapeutic efficacy and with acceptable host toxicity for each tumor type. Examples of combinations include cisplatin-containing regimens for non-small cell lung cancer (NSCLC); 5-FU, leucovorin, and irinotecan for colon cancer; and anthracyclines, carboplatin, and paclitaxel for breast cancer. In advanced OCC, conventional cytotoxic drugs most commonly used include methotrexate, cisplatin, carboplatin, 5-FU, paclitaxel, and docetaxel (Specenier and Vermorken, 2010). Whether given alone or in combination, these chemotherapy drugs have produced clinical benefits in terms of substantial improvement of the overall survival in OCC patients when compared to other cancers notorious to be refractory to chemotherapy such as colorectal and renal carcinomas (Lebwohl and Canetta, 1998; Jassem, 1999; Giaccone, 2000). However, even in the most chemotherapy responsive cases, patients inevitably experience tumor progression or relapses due to the development of cells with acquired drug resistance, or emergence of cell subpopulations genetically refractory to the drugs (intrinsic drug resistance; Greenberg et al., 2003). Although there is a relatively common pattern of genomic abnormalities including DNA allelic loss during OCC progression from premalignant to malignant phenotype such as chromosomal losses at 3p, 9p, 17p, and mutations in TP53, supporting a distinct biology for OCC (Mao et al., 1996; Mydlarz et al., 2010), drug resistance is predictable given the common presence of genomic instability that can result in the accumulation of multiple genetic aberrations including those that impact chemotherapy response signaling (Califano et al., 1996, 2000; Weber et al., 1998; Okafuji et al., 2000).

The limitation of chemotherapy has been ascribed primarily to mechanisms that mediate drug resistance at the cellular level or factors innate to tumor microenvironment and the host. For instance, a variety of intracellular mechanisms have been associated with decreased drug transport or increased efflux including overexpression of plasma membrane efflux transport proteins (e.g., P-glycoprotein-170, Pgp170; MDR-related proteins - MRP; lung resistance protein - LRP) that prevent drugs from reaching intracellular targets (Trédan et al., 2007). Other mechanisms involved in drug metabolism and cellular response to DNA damage are equally important in the development of drug resistance; these include enhanced drug detoxification via upregulation of phase II detoxifying enzymes (e.g., glutathione $S$-transferases), enhanced DNA repair mechanisms that counteract drug-induced DNA damage, mutations in drug target-encoding genes that reduce the affinity of a drug to active site (e.g., mutations in tubulin and topoisomerase-coding genes that reduce taxanes and camptothecin activity, respectively), as well as a plethora of other mechanisms that make the cells more resistant to pro-apoptotic signals ranging from aberrant function of growth factor receptors and tumor suppressors to deregulated intracellular transduction pathways, cell cycle checkpoints, and chromatin and transcriptional modifications (Rudolf and Cervinka, 2003).

Tumor microenvironment is critical determinant and modifier of therapeutic response; in particular angiogenesis and hypoxia have been extensively investigated as alternatives to overcome drug resistance (Folkman, 2007; Sebens and Schäfer, 2011; Maione et al., 2012; Semenza, 2012). To reach tumor cell sanctuaries in primary or distant tissue targets, anticancer drugs must be delivered efficiently through the tumor vasculature, cross the vessel wall, and diffuse within tumor tissue. This would argue that proangiogenic drugs would favor superior chemotherapy drug pharmacodistribution. However, approaches to inhibit angiogenesis have been investigated as alternatives to overcome drug resistance (Maione et al., 2012). In this context, the concept of metronomic chemotherapy dosing based on the use of repeated low-dose 
chemotherapy combined with antiangiogenic drugs has provided exciting results in preclinical models to minimize side effects of conventional chemotherapy and to improve therapeutic response in drug-resistant tumors (Browder et al., 2000; Hanahan et al., 2000; Bocci et al., 2002; Moreno Garcia et al., 2012) although the efficacy of this approach remains debated. While initial optimism targeting angiogenesis was based on the notion that endothelial cells are genetically stable and hence less prone to develop drug resistance, it is now documented that tumor blood vessels are instable and differ from their normal counterparts with respect to morphological characteristics, blood flow, leakiness, as well as structural abnormalities in the basement membrane and in pericyte activity (Morikawa et al., 2002; Kawamoto et al., 2012). This would explain the common occurrence of tumor endothelial cell resistance to antiangiogenic drugs, including the anti-VEGF antibody bevacizumab (Ma and Waxman, 2008). As noted above, inhibition of angiogenesis has a drawback as it may prevent drug distribution within tumor tissue. Moreover, unexpected observations from preclinical studies revealed that antiangiogenic drugs can either improve or worsen prognosis (Rapisarda and Melillo, 2012). The most obvious effect is the induction of cell hypoxia, a hallmark of tumor aggressiveness and resistant to chemoradiotherapy. For instance, recent study by Cooke et al. (2012) revealed that antiangiogenic agents have a beneficial decrease in the growth of primary tumors, but also can promote distant metastases and hence worsen prognosis. This was attributed to activation of cell invasion signaling, including epithelial-mesenchymal transition (EMT) and hypoxia in tumors depleted from tumor vessel-associated cells such as pericytes within the tumor microenvironment (Cooke et al., 2012). Hypoxia is well documented to promote resistance to chemotherapy and radiation (Braybrooke et al., 2000; Semenza, 2010, 2012). Hyperbaric oxygen (HBO) has been proposed to reduce tumor hypoxia by increasing the amount of dissolved oxygen in the plasma, however $\mathrm{HBO}$ is associated with significant adverse effects including oxygen toxic seizures and severe radiation tissue injury (Bennett et al., 2008). Tumor cell heterogeneity is another important aspect for chemotherapy failure once that chemotherapy targeting more sensitive tumor cell subpopulations can select rare variants with intrinsic resistance; this idea has been used to explain the intrinsic resistance of cancer stem-cells (CSC; Figure 1).

\section{EMT AND CSC CONCEPTS AND THEIR IMPACT ON DRUG RESISTANCE}

Traditional cancer treatments were developed by virtue of their anticancer activity against a tumor mass cell population (e.g., log kill-based principle). The tumor mass represents several subpopulations of cells with distinct genotypes and phenotypes, including response to chemotherapy. It is recognized that tumor heterogeneity contributes by several mechanisms, including activation of the EMT. In this case well-differentiated cancer cells require a higher plasticity and invasive capacity via a conversion to non-polarized and poorly differentiated mesenchymal cells (Thiery, 2002). Activated EMT signaling pathways (e.g., activation of $\mathrm{Wnt} / \beta$-catenin, PI3-K/AKT, MAPK, and Notch) is well documented to occur in advanced OCC (Boyer et al., 2000; Conacci-Sorrell et al., 2002; Nelson and Nusse, 2004; Larue and Bellacosa, 2005; Nawshad et al., 2005; Tommasi et al., 2007; Barker, 2008; Agarwal et al., 2010; Courtney et al., 2010; Falasca, 2010; Ihle and Powis, 2010; Wong et al., 2010). Preclinical studies also reported a significant correlation between EMT phenotype, drug resistance, and relapses (Zeisberg and Neilson, 2009) including in OCC patients (Machiels and Schmitz, 2011; Raza et al., 2011).

Equally important, the concept of CSC provided alternative frameworks to explain drug resistance and relapses. CSC is defined as a small subpopulation of tumor cells having both tumorinitiating ability and the ability to reconstitute the cellular heterogeneity of the original tumor. Several studies have implicated $\mathrm{CSC}$ in cancer progression, invasion process, loco-regional recurrence after therapy, and distant metastasis (Prince et al., 2007). Also, cancer cell variants expressing CSC markers have been reported to be more resistant to chemotherapy than cells that do not express CSC markers (Dean et al., 2005). This implies that chemotherapy drugs, by targeting the most sensitive nonCSC can contribute to enrichment of the chemotherapy-resistant CSC and hence promote recurrences (Frame and Maitland, 2011). This resistance may reflect the preservation of normal stem cell protective mechanisms, such as an increased expression of drug efflux pumps or alterations in apoptotic, cell cycle, and DNA repair mechanisms (Kvinlaug and Huntly, 2007). Interestingly, EMT which also promotes drug resistance is found to contribute to selection/enrichment of cell subpopulations with stem cell characteristics from well-differentiated epithelial cells (Mani et al., 2008; Polyak and Weinberg, 2009). Therefore several emerging approaches targeting key signaling molecules critical to CSC, and cancer epigenetics and metabolism are under extensive investigation (Grskovic et al., 2011; Vander Heiden, 2011; Arrowsmith et al., 2012).

\section{EMERGING THERAPEUTIC OPTIONS FOR ADVANCED OCC}

Conventional chemotherapy is widely used for refractory OCC despite only incremental improvement in disease-free survival. The broad diversity of drug resistance mechanisms led to alternative approaches incorporating drug resistance modulators in the chemotherapy regimens. Possible mechanisms of acquired resistance include altered cellular drug transport (e.g., inhibitors of $P$-glycoprotein 170 encoded by the MDR1), enhanced intracellular detoxification, increased DNA repair, and enhanced tolerance to DNA damage (Persons et al., 1999; Garraway and Jänne, 2012). However, this approach has limited success given the large number of genetic changes affecting multiple cell regulatory pathways that regulate drug response. Moreover, recurrent OCC treated by chemotherapy often expresses an aggressive progression and develop cross-resistance to a wide range of structurally and mechanistically unrelated drugs (Garraway and Jänne, 2012). This is a limitation in the use of alternative therapeutic combinations since the process of selecting treatment has been based on the availability of chemotherapy agents, as well as different drug modes of action.

The great progress in the understanding of cancer biology has led to the development and validation of several target-selective agents referred as targeted therapies with improved efficacy against chemotherapy refractory cancers. These classes of drugs have selectivity toward targets proven to play a rate-limiting step in 

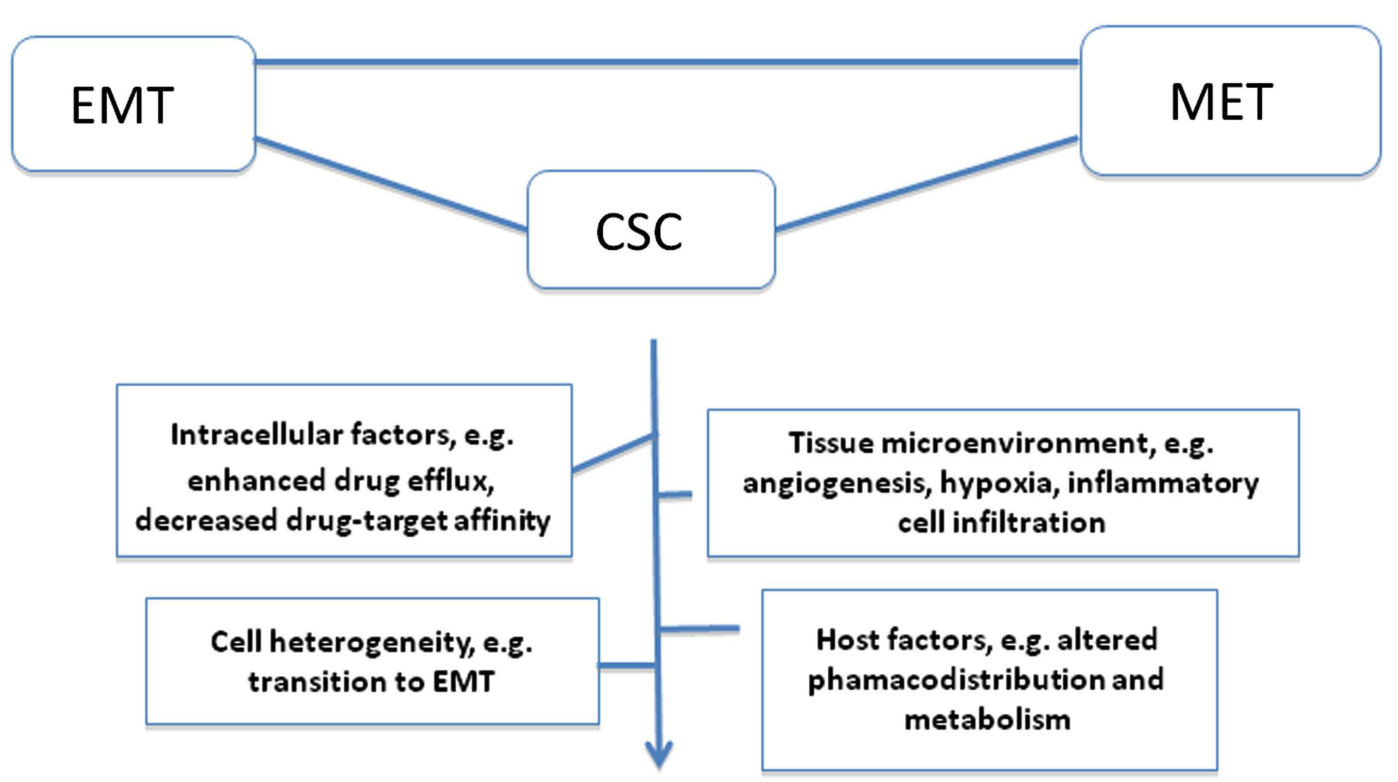

\section{Susceptibility to drug response and relapses}

FIGURE 1 | Representative important factors and concepts implicated in drug resistance and relapses. Various intracellular factors can account for impaired OCC cell response to chemotherapy drugs, including changes in the bioavailability of a drug or its active metabolites at the target site (decreased uptake or increased efflux), inability of cells to repair DNA damage which can lead to increase tolerance, and defects in cell ability to signal DNA damage response to downstream effectors targets to trigger cell death. Altered drug pharmacodistribution and pharmacodynamics in the host also impact on drug response. The selective pressure exerted by drugs combined with tumor cell heterogeneity (often a result of tumor genomic instability) is also a driving force for drug resistance. Tumors can develop resistance via regulation of their microenvironment, e.g., by remodeling the extracellular matrix, deregulating cancer cell-endothelial cell/immune infiltrating cell interactions, leading to enhanced angiogenesis, hypoxia, and resistance to cell death. In this context, epithelial-mesenchymal transition (EMT) and the reverse process mesenchymal-epithelial transition (MET), both are critical process for cancer progression to metastasis and homing in distant site contribute to drug resistance via various mechanisms, including induction of cell heterogeneity and selection of rare cancer stem cell (CSC) variants with intrinsic resistance to chemotherapy. the process of cancer progression and many are in the clinical use for specific cancers, e.g., EGFR-tyrosine kinase inhibitor Tarceva (Erlotinib for invasive NSCLC and pancreatic cancer (Rosell et al., 2012; Troiani et al., 2012); anti-EGFR monoclonal antibody Cetuximab (Erbitux) for colorectal carcinoma (Debucquoy et al., 2010); the monoclonal antibody Trastuzumab (Herceptin) for HER2/neu+ breast cancer (Chang, 2010); several B-Raf inhibitors for melanoma (Lott, 2011); antiangiogenesis agents such as the antiVEGF monoclonal antibody Bevacizumab (Avastin) for metastatic cancers of the lung, colon, and kidney (Kerr, 2004); the proteasome inhibitor Bortezomib (Velcade) for multiple myeloma (Mahindra et al., 2012); the histone deacetylase inhibitor Vorinostat (Zolinza) for cutaneous lymphoma (Lansigan and Foss, 2010); and the BcrAbl inhibitors including Gleevec for chronic myeloid leukemia (CML). In the case of OCC, the clinical use of targeted agents is still lagging behind but ongoing multi-institutional clinical trials are being conducted to investigate their utility compared to conventional cytotoxic chemotherapy (Table 1). Given that most of the targeted agents cited above, including those targeting EGFR and HER-2 receptors, VEGF and VEGFR, Raf, and proteasome, are also deregulated in OCC, they may provide potential therapeutic benefits for patients with advanced OCC. Moreover, a current alternative in oncology research is to improve the therapeutic efficacy of existing chemotherapy agents focusing on combination of targeted agents with cytotoxics drugs, or their use as long-term maintenance therapy (either low dose/high frequency of standard cytotoxic drugs or molecularly targeted agents like Avastin, Herceptin, Erlotinib) following high-dose induction therapy, the initial treatment used to reduce tumor $\operatorname{size}^{2}$ [National Cancer Institute at National Institutes of Health (NCI; 2012)]. In this way, OCC could certainly benefit from advanced funding from other cancer types particularly because the suitability of OCC for multiple biopsies that can aid target profiling and patients selection.

\section{CONCLUSION AND PERSPECTIVES}

The efficacy of conventional cytotoxic chemotherapy for OCC has been hampered by lack of selectivity, narrow therapeutic margin, and the common development of drug resistance mechanisms. Due to the broad multifactorial aspect of drug resistance phenotype, it is not surprising that the initial optimism surrounding modulation of a single drug resistance marker to overcome resistance in several other cancers has waned. Likewise, advances in

\footnotetext{
${ }^{2}$ http://www.cancer.gov/dictionary?cdrid $=45736 \mathrm{NCI}$
} 
Table 1 | Recent drugs, targets, and clinical trials in head and neck cancers.

\begin{tabular}{|c|c|c|c|}
\hline Class of drugs & Commercial name & Target & Head and neck clinical trials \\
\hline E7080 & & VEGFR2 & Phase II \\
\hline Erlotinib & Tarceva & EGFR & Phase III \\
\hline Imatinib & Gleevac & PDGFR, BCR-ABL, KIT & Phase II \\
\hline Lapatinib & Tykerb & EGFR & Phase III \\
\hline Sunitinib & Sutin & VEGFR, PDGFR, KIT, FLT-3 RET & Phase II \\
\hline Vandetanib & Zactima & VEGFR, RET,EGFR & Phase $\|/\| \|$ \\
\hline$X L-184$ & & MET, VEGFR, RET & Phase III \\
\hline Bexarotene & Targretin & $\mathrm{RXR}$ & Pilot study \\
\hline Irofulven + capecitabine & MGI-114 + Xeloda & p53, MDR1 & Phase III \\
\hline Trastuzumab & Herceptin & ErbB2 & Phase II \\
\hline Zalutumumab & HuMax-EGFr & EGFR & Phase III \\
\hline Temsirolimus & Torisel & mTOR (PI3k) & Phase II \\
\hline Bortezomib & Velcade & 26s Proteasome inhibitor & Phase II \\
\hline Valproic & & Acid epigenetic alterations & Phase II \\
\hline Oxaliplatin & Eloxatin & Induction of Bax/Bak & Phase II \\
\hline Docetaxel & Taxotere & Microtubules & Phase III \\
\hline
\end{tabular}

(NCl www.cancer.gov/clinicaltrials website).

molecular biology and drug discovery technologies have led to the development of pharmacologic agents and therapeutic antibodies that selectively target crucial signaling molecules with preferential expression on malignant cells, or their surrounding tissue microenvironment. Clinical experience with several targeted drugs, including small molecules and therapeutic antibodies, revealed agents that can be better tolerated and it offers advantage in the identification of subsets of patients who can be benefit during the treatment. Furthermore, the shift toward targeted agents has potential to establish a novel framework, which can be used to develop alternative strategies to identify druggable tumor target. These targets can be adapted to individual cases with greater potential to counter critical drug resistance mechanisms (Garraway and Jänne, 2012), e.g., specific mutations in EGFR in NSCLC or B-Raf in melanoma can predict either sensitivity or resistance. Equally important and as described above, unexpected observations from preclinical studies clearly support the necessity to evaluate carefully the endpoints used to analyze the therapeutic utility of targeted agents. Targeted agents such as antiangiogenic drugs may lead to double edged effects by either improving or worsening prognosis (Cooke et al., 2012; Rapisarda and Melillo, 2012).

\section{REFERENCES}

Agarwal, R., Carey, M., Hennessy, B., and Mills, G. B. (2010). PI3K pathwaydirected therapeutic strategies in cancer. Curr. Opin. Investig. Drugs $11,615-628$.
Agra, I. M., Filho, J. G., Martins, E. P., and Kowalski, L. P. (2010). Second salvage surgery for rerecurrent oral cavity and oropharynx carcinoma. Head Neck 32, 997-1002.

It is clear that a better understanding of the molecular and biological profile of OCC should facilitate the development of more efficient targeted therapies. Current clinical trials with targeted agents in OCC are likely to bring promising directions decreasing the risk of tumor recurrence and improving survival of patients with advanced OCC. Equally important, OCC represent an interesting clinical model to address translational aspects of drug relapses and new agents. Unlike cell lines and transplantation models, which revealed limited predictive clinical value possibly due to genetic and physiological differences between animal and human (Gillet et al., 2011), OCC is generally an accessible disease since multiple biopsies are feasible compared to other tumors location. This would allow for monitoring predictive molecular targets of utmost importance to clinical drug response versus relapses. These are critical issues for the development of efficient personalized therapy and in identification of novel therapeutic targets as well as monitoring the course and status of the disease.

\section{ACKNOWLEDGMENTS}

Work cited from these investigators has been supported by the Canadian Institutes for Health Research (CIHR), the Canadian Cancer Society, and the Quebec Breast Cancer Foundation.

Alaoui-Jamali, M. A., Dupré, I., and Qiang, H. (2004). Prediction of drug sensitivity and drug resistance in cancer by transcriptional and proteomic profiling. Drug Resist. Updat. 7, 245-255.
Arrowsmith, C. H., Bountra, C., Fish, P. V., Lee, K., and Schapira, M. (2012). Epigenetic protein families: a new frontier for drug discovery. Nat. Rev. Drug Discov. 11, $384-400$. 
Barker, N. (2008). The canonical WNT/beta-catenin signalling pathway. Methods Mol. Biol. 468, 5-15.

Bennett, M., Feldmeier, J., Smee, R., and Milross, C. (2008). Hyperbaric oxygenation for tumor sensitisation to radiotherapy: a systematic review of randomised controlled trials. Cancer Treat. Rev. 34, 577-591.

Bernier, J., Bonner, J., Vermorken, J. B., Bensadoun, R. J., Dummer, R., Giralt, J., Kornek, G., Hartley, A., Mesia, R., Robert, C., Segaert, S., and Ang, K. K. (2008). Consensus guidelines for the management of radiation dermatitis and coexisting acnelike rash in patients receiving radiotherapy plus EGFR inhibitors for the treatment of squamous cell carcinoma of the head and neck. Ann. Oncol. 19, 142-149.

Bocci, G., Nicolaou, K. C., and Kerbel, R. S. (2002). Protracted low-dose effects on human endothelial cell proliferation and survival in vitro reveal a selective antiangiogenic window for various chemotherapeutic drugs. Cancer Res. 62, 6938-6943.

Boyer, B., Valles, A. M., and Edme, N. (2000). Induction and regulation of epithelial-mesenchymal transitions. Biochem. Pharmacol. 60, 1091-1099. Braybrooke, J. P., O’Byrne, K. J., Propper, D. J., Blann, A., Saunders, M., Dobbs, N., Han, C., Woodhull, J., Mitchell, K., Crew, J., Smith, K., Stephens, R., Ganesan, T. S., Talbot, D. C., and Harris, A. L. (2000). A phase II study of razoxane, an antiangiogenic topoisomerase II inhibitor, in renal cell cancer with assessment of potential surrogate markers of angiogenesis. Clin. Cancer Res. 6, 4697-4704.

Browder, T., Butterfield, C. E., Kräling, B. M., Shi, B., Marshall, B., O'Reilly, M. S., and Folkman, J. (2000). Antiangiogenic scheduling of chemotherapy improves efficacy against experimental drug-resistant cancer. Cancer Res. 60, 1878-1886.

Califano, J., van der Riet, P., Westra, W., Nawroz, H., Clayman, G., Piantadosi, S., Corio, R., Lee, D., Greenberg, B., Koch, W., and Sidransky, D. (1996). Genetic progression model for head and neck cancer: implications for field cancerization. Cancer Res. 56, 2488-2492.

Califano, J., Westra, W. H., Meininger, G., Corio, R., Koch, W. M., and Sidransky, D. (2000). Genetic progression and clonal relationship of recurrent premalignant head and neck lesions. Clin. Cancer Res. 6, 347-352.

Carvalho, A. L., Kowalski, L. P., Agra, I. M., Pontes, E., Campos, O. D., and Pellizzon, A. C. (2005). Treatment results on advanced neck metastasis (N3) from head and neck squamous carcinoma. Otolaryngol. Head Neck Surg. 132, 862-868.

Chang, H. R. (2010). Trastuzumabbased neoadjuvant therapy in patients with HER2-positive breast cancer. Cancer 116, 2856-2867.

Conacci-Sorrell, M., Zhurinsky, J., and Ben-Ze'Ev, A. (2002). The cadherincatenin adhesion system in signaling and cancer. J. Clin. Invest. 109, 987-991.

Cooke, V. G., LeBleu, V. S., Keskin, D., Khan, Z., O'Connell, J. T., Teng, Y., Duncan, M. B., Xie, L., Maeda, G., Vong, S., Sugimoto, H., Rocha, R. M., Damascena, A., Brentani, R. R., and Kalluri, R. (2012). Pericyte depletion results in hypoxia-associated epithelial-tomesenchymal transition and metastasis mediated by met signaling pathway. Cancer Cell 21, 66-82.

Courtney, K. D., Corcoran, R. B., and Engelman, J. A. (2010). The PI3K pathway as drug target in human cancer. J. Clin. Oncol. 28, 1075-1083.

Dean, M., Fojo, T., and Bates, S. (2005). Tumor stem cells and drug resistance. Nat. Rev. Cancer 5, 275-284.

Debucquoy, A., Machiels, J. P., McBride, W. H., and Haustermans, K. (2010). Integration of epidermal growth factor receptor inhibitors with preoperative chemoradiation. Clin. Cancer Res. 16, 2709-2714.

Falasca, M. (2010). PI3K/Akt signalling pathway specific inhibitors: a novel strategy to sensitize cancer cells to anti-cancer drugs. Curr. Pharm. Des. 16, 1410-1416.

Fan, S., Tang, Q. L., Lin, Y. J., Chen, W. L., Li, J. S., Huang, Z. Q., Yang, Z. H., Wang, Y. Y., Zhang, D. M., Wang, H. J., Dias-Ribeiro, E., Cai, Q., and Wang, L. (2011). A review of clinical and histological parameters associated with contralateral neck metastases in oral squamous cell carcinoma. Int. J. Oral Sci. 3, 180-191.

Folkman, J. (2007). Angiogenesis: an organizing principle for drug discovery? Nat. Rev. Drug Discov. 6, 273-286.

Frame, F. M., and Maitland, N. J. (2011). Cancer stem cells, models of study and implications of therapy resistance mechanisms. Adv. Exp. Med. Biol. 720, 105-118.

Furness, S., Glenny, A. M., Worthington, H. V., Pavitt, S., Oliver, R., Clarkson, J. E., Macluskey, M., Chan, K. K., and Conway, D. I. (2011). Interventions for the treatment of oral cavity and oropharyngeal cancer: chemotherapy. Cochrane Database Syst. Rev. 4, CD006386.
Garraway, L. A., and Jänne, P. A. (2012). Circumventing cancer drug resistance in the era of personalized medicine. Cancer Discov. 2 , 214-226.

Garzino-Demo, P., Dell'Acqua, A., Dalmasso, P., Fasolis, M., La Terra Maggiore, G. M., Ramieri, G., Berrone, S., Rampino, M., and Schena, M. (2006). Clinicopathological parameters and outcome of 245 patients operated for oral squamous cell carcinoma. J. Craniomaxillofac Surg. 34 344-350.

Giaccone, G. (2000). Clinical perspectives on platinum resistance. Drugs 59, 37-38.

Gillet, J. P., Calcagno, A. M., Varma, S. Marino, M., Green, L. J., Vora, M. I., Patel, C., Orina, J. N., Eliseeva, T. A., Singal, V., Padmanabhan, R., Davidson, B., Ganapathi, R., Sood, A. K., Rueda, B. R., Ambudkar, S V., and Gottesman, M. M. (2011). Redefining the relevance of established cancer cell lines to the study of mechanisms of clinical anti-cancer drug resistance. Proc. Natl. Acad. Sci. U.S.A. 108, 18708-18713.

Greenberg, J. S., El-Naggar, A. K., Mo, V., Roberts, D., and Myers, J. N. (2003). Disparity in pathologic and clinical lymph node staging in oral tongue carcinoma. Implication for therapeutic decision making. Cancer 98 508-515.

Grskovic, M., Javaherian, A., Strulovici, B., and Daley, G. Q. (2011). Induced pluripotent stem cells - opportunities for disease modelling and drug discovery. Nat. Rev. Drug Discov. 10 915-929.

Hanahan, D., Bergers, G., and Bergsland, E. (2000). Less is more, regularly: metronomic dosing of cytotoxic drugs can target tumor angiogenesis in mice. J. Clin. Invest. 105, 1045-1047.

Ihle, N. T., and Powis, G. (2010). Inhibitors of phosphatidylinositol3-kinase in cancer therapy. Mol. Aspects Med. 31, 135-144.

Jassem, J. (1999). Chemotherapy of advanced non-small cell lung cancer. Ann. Oncol. 10, 77-82.

Kawamoto, T., Ohga, N., Akiyama, K., Hirata, N., Kitahara, S., Maishi, N., Osawa, T., Yamamoto, K., Kondoh, M., Shindoh, M., Hida, Y., and Hida, K. (2012). Tumorderived microvesicles induce proangiogenic phenotype in endothelial cells via endocytosis. PLoS ONE 7 , doi:10.1371/journal.pone.0034045

Kerr, D. J. (2004). Targeting angiogenesis in cancer: clinical development of bevacizumab. Nat. Clin. Pract. Oncol. 1, 39-43.
Kowalski, L. P., Carvalho, A. L., Martins Priante, A. V., and Magrin, J. (2005). Predictive factors for distant metastasis from oral and oropharyngeal squamous cell carcinoma. Oral Oncol. 41, 534-541.

Kowalski, L. P., Magrin, J., Sabóia, M., Santos, J. C., and Torloni, H. (1998). Squamous cell carcinoma of the tongue: a review of 629 patients treated at a single institution. South Am. J. Cancer 107, 697-702.

Kvinlaug, B. T., and Huntly, B. J. (2007). Targeting cancer stem cells. Expert Opin. Ther. Targets 11, 915-927.

Lansigan, F., and Foss, F. M. (2010). Current and emerging treatment strategies for cutaneous T-cell lymphoma. Drugs 70, 273-286.

Larue, L., and Bellacosa, A. (2005). Epithelial-mesenchymal transition in development and cancer: role of phosphatidylinositol 3' kinase/AKT pathways. Oncogene 24, 7443-7454.

Lebwohl, D., and Canetta, R. (1998). Clinical development of platinum complexes in cancer therapy: an historical perspective and an update. Eur. J. Cancer 34, 1522-1534.

Leemans, C. R., Tiwari, R., Nauta, J. J., van der Waal, I., and Snow, G. B. (1994). Recurrence at the primary site in head and neck cancer and the significance of neck lymph node metastases as a prognostic factor. Cancer 73, 187-190.

Lott, J. P. (2011). Vemurafenib in melanoma with BRAF V600E mutation. N. Engl. J. Med. 365, 1449-1450.

Ma, J., and Waxman, D. J. (2008). Combination of antiangiogenesis with chemotherapy for more effective cancer treatment. Mol. Cancer Ther. 7,3670-3684.

Machiels, J. P., and Schmitz, S. (2011) New advances in targeted therapies for squamous cell carcinoma of the head and neck. Anticancer Drugs 22, 626-633.

Mahindra, A., Laubach, J., Raje, N., Munshi, N., Richardson, P. G., and Anderson, K. (2012). Latest advances and current challenges in the treatment of multiple myeloma. Nat. Rev. Clin. Oncol. 9, $135-143$.

Maione, F., Capano, S., Regano, D. Zentilin, L., Giacca, M., Casanovas, O., Bussolino, F., Serini, G., and Giraudo, E. (2012). Semaphorin $3 \mathrm{~A}$ overcomes cancer hypoxia and metastatic dissemination induced by antiangiogenic treatment in mice. $J$. Clin. Invest. 125, 1832-1848.

Mani, S. A., Guo, W., Liao, M. J., Eaton, E. N., Ayyanan, A., Zhou, A. Y., Brooks, M., Reinhard, F., 
Zhang, C. C., Shipitsin, M., Campbell, L. L., Polyak, K., Brisken, C., Yang, J., and Weinberg, R. A. (2008). The epithelial-mesenchymal transition generates cells with properties of stem cells. Cell 133, 704-715.

Mao, L., El-Naggar, A. K., Fan, Y. H., Lee, J. S., Lippman, S. M., Kayser, S., Lotan, R., and Hong, W. K. (1996). Telomerase activity in head and neck squamous cell carcinoma and adjacent tissues. Cancer Res. 56, 5600-5604.

Moreno Garcia, V., Basu, B., Molife, L. R., and Kaye, S. B. (2012). Combining antiangiogenics to overcome resistance: rationale and clinical experience. Clin. Cancer Res. 18, 3750-3761.

Morikawa, S., Baluk, P., Kaidoh, T., Haskell, A., Jain, R. K., and McDonald, D. M. (2002). Abnormalities in pericytes on blood vessels and endothelial sprouts in tumors. Am. J. Pathol. 160, 985-1000.

Mydlarz, W. K., Hennessey, P. T., and Califano, J. A. (2010). Advances and perspectives in the molecular diagnosis of head and neck cancer. Expert Opin. Med. Diagn. 4, 53-65.

Nawshad, A., Lagamba, D., Polad, A., and Hay, E. D. (2005). Transforming growth factor-beta signaling during epithelial-mesenchymal transformation: implications for embryogenesis and tumor metastasis. Cells Tissues Organs (Print) 179, 11-23.

Nelson, W. J., and Nusse, R. (2004). Convergence of WNT, $\beta$-catenin, and cadherin pathways. Science 303, 1483-1487.

Okafuji, M., Ita, M., Oga, A., Hayatsu, Y., Matsuo, A., Shinzato, Y., Shinozaki, F., and Sasaki, K. (2000). The relationship of genetic aberrations detected by comparative genomic hybridization to DNA ploidy and tumor size in human oral squamous cell carcinomas. J. Oral Pathol. Med. 29, 226-231.

Parkin, D. M., Bray, F., Ferlay, J., and Pisani, P. (2005). Global cancer statistics, 2002. CA Cancer J. Clin. 55, 74-108.

Persons, D. L., Yazlovitskaya, E. M., Cui, W., and Pelling, J. C. (1999). Cisplatin-induced activation of mitogen-activated protein kinases in ovarian carcinoma cells: inhibition of extracellular signal-regulated kinase activity increases sensitivity to cisplatin. Clin. Cancer Res. 5, 1007-1014.

Petersen, P. E. (2009). Oral cancer prevention and control - the approach of the World Health Organization. Oral Oncol. 45, 454-460.

Polyak, K., and Weinberg, R. A. (2009). Transitions between epithelial and mesenchymal states: acquisition of malignant and stem cell traits. Nat. Rev. Cancer 9, 265-273.

Prince, M. E., Sivanandan, R., Kaczorowski, A., Wolf, G. T., Kaplan, M. J., Dalerba, P., Weissman, I. L., Clarke, M. F., and Ailles, L. E. (2007). Identification of a subpopulation of cells with cancer stem cell properties in head and neck squamous cell carcinoma. Proc. Natl. Acad. Sci. U.S.A. 104, 973-978.

Rapisarda, A., and Melillo, G. (2012). Overcoming disappointing results with antiangiogenic therapy by targeting hypoxia. Nat. Rev. Clin. Oncol. 9, 378-390.

Raza, S., Kornblum, N., Kancharla, V. P., Baig, M. A., Singh, A. B., and Kalavar, M. (2011). Emerging therapies in the treatment of locally advanced squamous cell cancers of head and neck. Recent Pat. Anticancer Drug. Discov. 6, 246-257.

Rosell, R., Carcereny, E., Gervais, R. Vergnenegre, A., Massuti, B., Felip, E., Palmero, R., Garcia-Gomez, R., Pallares, C., Sanchez, J. M., Porta, R., Cobo, M., Garrido, P., Longo, F., Moran, T., Insa, A., De Marinis, F., Corre, R., Bover, I., Illiano, A., Dansin, E., de Castro, J., Milella, M., Reguart, N., Altavilla, G., Jimenez, U., Provencio, M., Moreno, M. A., Terrasa, J., Muñoz-Langa, J., Valdivia, J., Isla, D., Domine, M., Molinier, O., Mazieres, J., Baize, N., Garcia-Campelo, R., Robinet, G., Rodriguez-Abreu, D., LopezVivanco, G., Gebbia, V., FerreraDelgado, L., Bombaron, P., Bernabe, R., Bearz, A., Artal, A., Cortesi, E., Rolfo, C., Sanchez-Ronco, M., Drozdowskyj, A., Queralt, C., de Aguirre, I., Ramirez, J. L., Sanchez, J. J., Molina, M. A., Taron, M., PazAres, L., and Spanish Lung Cancer Group in collaboration with Groupe Français de Pneumo-Cancérologie and Associazione Italiana Oncologia Toracica. (2012). Erlotinib versus standard chemotherapy as firstline treatment for European patients with advanced EGFR mutationpositive non-small-cell lung cancer (EURTAC): a multicentre, openlabel, randomised phase 3 trial. Lancet Oncol. 13, 239-246.

Rudolf, E., and Cervinka, M. (2003). Topoisomerases and tubulin inhibitors: a promising combination for cancer treatment. Curr. Med. Chem. Anticancer Agents 3, 421-429.

Sebens, S., and Schäfer, H. (2011). The tumor stroma as mediator of drug resistance - a potential target to improve cancer therapy? Curr. Pharm. Biotechnol. [Epub ahead of print]

Semenza, G. L. (2010). Defining the role of hypoxia-inducible factor 1 in cancer biology and therapeutics. Oncogene 29, 625-634.

Semenza, G. L. (2012). Hypoxiainducible factors in physiology and medicine. Cell 2012 148, 399-408.

Specenier, P., and Vermorken, J. B. (2010). Advances in the systemic treatment of head and neck cancers. Curr. Opin. Oncol. 22, 200-205.

Su, H. H., Chu, S. T., Hou, Y. Y., Chang, K. P., and Chen, C. J. (2006). Spindle cell carcinoma of the oral cavity and oropharynx: factors affecting outcome. J. Chin. Med. Assoc. 69, 478-483.

Thiery, J. P. (2002). Epithelialmesenchymal transitions in tumor progression. Nat. Rev. Cancer 2, 442-454.

Tommasi, S., Pinto, R., Pilato, B., and Paradiso, A. (2007). Molecular pathways and related target therapies in liver carcinoma. Curr. Pharm. Des. 13, 3279-3287.

Trédan, O., Galmarini, C. M., Patel, K. and Tannock, I. F. (2007). Drug resistance and the solid tumor microenvironment. J. Natl. Cancer Inst. 99 , 1441-1454.

Troiani, T., Martinelli, E., Capasso, A. Morgillo, F., Orditura, M., De Vita, F., and Ciardiello, F. (2012). Targeting EGFR in Pancreatic Cancer Treatment. Curr. Drug Targets 13 , 802-810.

Vander Heiden, M. G. (2011). Targeting cancer metabolism: a therapeutic window opens. Nat. Rev. Drug Discov. 10, 671-684.

Vermorken, J. B., Remenar, E., van Herpen, C., Gorlia, T., Mesia, R., Degardin, M., Stewart, J. S., Jelic, S., Betka, J., Preiss, J. H., van den Weyngaert, D., Awada, A., Cupissol, D.,
Kienzer, H. R., Rey, A., Desaunois, I., Bernier, J., and Lefebvre, J. L. (2007). Cisplatin, fluorouracil, and docetaxel in unresectable head and neck cancer. N. Engl. J. Med. 357, 1695-1704.

Weber, R. G., Scheer, M., Born, I. A., Joos, S., Cobbers, J. M., Hofele, C., Reifenberger, G., Zöller, J. E., and Lichter, P. (1998). Recurrent chromosomal imbalances detected in biopsy material from oral premalignant and malignant lesions by combined tissue microdissection, universal DNA amplification, and comparative genomic hybridization. Am. J. Pathol. 153, 295-303.

Wong, K. K., Engelman, J. A., and Cantley, L. C. (2010). Targeting the PI3K signaling pathway in cancer. Curr. Opin. Genet. Dev. 20, 87-90.

Woolgar, J. A., Rogers, S., West, C. R., Errington, R. D., Brown, J. S., and Vaughan, E. D. (1999). Survival and patterns of recurrence in 200 oral cancer patients treated by radical surgery and neck dissection. Oral Oncol. 35, 257-265.

Zeisberg, M., and Neilson, E. G. (2009). Biomarkers for epithelialmesenchymal transitions. J. Clin. Invest. 119, 1429-1437.

Conflict of Interest Statement: The authors declare that the research was conducted in the absence of any commercial or financial relationships that could be construed as a potential conflict of interest.

Received: 15 June 2012; paper pending published: 08 July 2012; accepted: 12 July 2012; published online: 30 July 2012. Citation: da Silva SD, Hier $M$, Mlynarek A, Kowalski LP and AlaouiJamali MA (2012) Recurrent oral cancer: current and emerging therapeutic approaches. Front. Pharmacol. 3:149. doi: 10.3389/fphar.2012.00149

This article was submitted to Frontiers in Pharmacology of Anti-Cancer Drugs, a specialty of Frontiers in Pharmacology. Copyright (c) 2012 da Silva, Hier, Mlynarek, Kowalski and Alaoui-Jamali. This is an open-access article distributed under the terms of the Creative Commons Attribution License, which permits use, distribution and reproduction in other forums, provided the original authors and source are credited and subject to any copyright notices concerning any third-party graphics etc. 